\title{
ReliefWeb: Mandate and Objectives
}

\author{
Sharon Ruso
}

\section{Résumé}

Cet article donne un aperçu de ReliefWeb, projet mené en matière d'alerte préventive par le Département des Affaires Humanitaires des Nations Unies basé à Genève. La structure et les grands objectifs du ReliefWeb y sont mis en évidence.

The UN Department of Humanitarian Affairs (DHA), established in 1992, aims to mobilize international community efforts to meet human needs in disasters and emergencies, to coordinate the response to complex humanitarian emergencies and sudden natural and technological disasters in a coherent and timely manner, and to promote disaster prevention and preparedness. In order to meet its responsibilities for ensuring that reliable information is available for the purposes of prevention, preparedness and rapid response, DHA has been requested by the international humanitarian community to develop an international global network for communication and information support known as ReliefWeb.

As an integral part of DHA's global strategy, ReliefWeb's mandate and objectives are:

- to act as the principal information system for prevention, preparedness, and rapid response for the humanitarian community;

- to ensure that UN system agencies, governments, other international organizations, and nongovernment organizations have access to such an information system at the earliest moment and preferably in advance of an emergency;

\footnotetext{
Sharon Ruso, Head, Information Services, United Nations Department of Humanitarian Affairs, Geneva.
}

- to ensure the availability of continuously updated information on disasters and humanitarian emergencies as they unfold in order to provide substantive support to decision making systems, with respect to relief, logistics, supply and contingency planning;

- to strengthen the capacity of all relevant actors, particularly in disaster and emergency-prone countries, to receive and use information more effectively in support of the development of complimentary approaches on prevention, relief activities and operations.

In pursuit of these objectives, ReliefWeb strategy will include:

- the development of an online distributed information system, easily and publicly available through existing networks and using the latest information technology;

- in support of such an online system and in the interests of timely and reliable information between and among principal actors during emergencies, the development of regional information centres capable of meeting the challenges of reporting both in advance of and during complex emergencies and disasters;

- the promotion of common standards for information collection, analysis, integration, exchange, and dissemination;

- the design and adoption of a system of alerts to ensure prompt and effective humanitarian responses;

- in support of current initiatives on prevention of conflicts, the development of a concrete information approach, through networking with regional actors like the Organization for African Unity (OAU), that focuses on the collection and dissemination of information on root causes of natural and complex humanitarian emergencies.

\section{Structure and Modalities}

ReliefWeb, when complete, will comprise two complementary structures. The first, ReliefWeb online via the Internet, is in development. The second, regionally-based information centres, is envisaged as part of a staggered development over five years. To fully comprehend the ReliefWeb concept of a global information network, these structures should be viewed as inter-independent and mutually supportive.

As an online distributed information system (http://www/reliefweb. int), ReliefWeb is easily and publicly available through the Internet and other networks that feature gateways to the Internet. Those who lack access to the World Wide Web will be linked via email through regional networks like Mango and Fido. However, such an online system, regardless of its sophistication, cannot alone support the diverse information needs of the humanitarian system.

To achieve superior value-added modalities, ReliefWeb will need to take additional steps. In this regard, a regional network of information centres is proposed which will be responsible for the collection, analysis, and dissemination of information both online and within the region by the most convenient means. During emergencies, these centres will be responsible for the deployment of emergency information units to ensure on-the-spot coverage of assistance activities through daily and as-needed dissemination of reports and alerts. Such an information network makes it easier to identify and define operational responsibilities that will be mutually supportive. It also has the advantage of representing the common interest and allows for the complementarity of activities that characterize assistance efforts during complex emergencies and natural dis- 
asters. Moreover, a regional base in high risk areas allows for areas of cooperation in the sharing and use of information based on lessons learned and in advance of an emergency.

These centres will draw on existing mandates and arrangements of the international humanitarian system. They will build upon the regional capacities of relevant organizations, helping to ensure the systematic pooling, analysis, and dissemination of information on natural disasters and other emergencies. Future sites should include the Great Lakes region of Africa, the Horn of Africa, the Sahel, the Caucasus, the Balkans and Latin America.

\section{Policy}

Those governmental, nongovernmental, international and UN agencies which together originally conceived of and helped to develop the ReliefWeb prototype have acted as a provisional Commission for the direction of ReliefWeb during its first eighteen months. Between November 1994 and January 1996, reporting has taken the form of two conferences and a working group meeting. Since August 1995, ReliefWeb's daily activities have been under the general direction of DHA, Geneva, where they continue under the overall supervision of the Director of the Chief Information and External Relations Branch. Ideally, ReliefWeb will soon take policy direction from the Inter-Agency Support Committee. (IASC), whose members are the Heads of the major UN and nongovernmental relief agencies. This solution would provide for direction at the highest level of involvement, and ensure that the network develops in ways consistent with the changing needs of the major international agencies responsible for humanitarian assistance, and that it is maintained and resourced accordingly. Effective coverage of policy implementation may be entrusted by the IASC to a Focus Group. The Focus Group would have responsibility for inter alia the establishment of policy directions including financial control, periodic assessments of system per- formance, sustainability, and appropriate fundraising appeals based on need and performance evaluations.

\section{Sources of Information}

In choosing information sources for ReliefWeb, the Project Team has been guided by the results of an information requirements analysis carried out in December 1995 and by the deliberations of a Working Group on Information (formed as a result of a recommendation issuing from the January 1996, Working Group Meeting in Geneva), whose membership represents the interests of major UN, international, governmental and nongovernmental relief agencies. The information required by the humanitarian community appears to fall in two broad categories: country situation reports and emergency/logistical. The principal needs of the main users (desk officers, logistics specialists, programme officers, planners, donors, and policy analysts) are to have available timely and trustworthy information upon which to prepare and respond to complex emergencies and natural disasters, as well as the longer term needs of those engaged in policy analysis, at all levels, and those concerned with research on root causes and conflict prevention.

\section{Access}

Ensuring rapid access to information is a major requirement of the ReliefWeb system. The responsibility for guiding the design of an electronic system that will ensure rapid access lies with the ReliefWeb Technical Working Group whose membership parallels that of the Information Working Group with the addition of representatives from UN Information Computing Centre (UNICC) and the International Telecommunications Union (ITU). This group will guide the activities of the Project Team in the development of a competent and easy-to-use search engine and support the Team's efforts for linking regional centres, daily updates, and the promotion of common technical standards between and among relief agencies.
In addition, the need for fast, reliable, and secure communications channels must also be addressed. ReliefWeb aims to ensure that such a system allows for specific and reliable communications channels between principal actors. Moreover, the system will also need to address those who are not yet able to access the Internet. How to effectively distribute the system regionally, where and what models to apply, are still in the planning stages.

Cooperation between agencies is a requisite for undertaking a project of this nature and scope. To ensure continuous and reliable updates of information for emergency management and related activities, ReliefWeb will necessarily rely on the information management resources of sister agencies. A sustainable system for such an endeavour began during the second phase of the ReliefWeb Project and will require further refinements hereafter.

\section{Country Situation Reports}

ReliefWeb will aim to become the central link to country situation reports and will focus on those areas of special interest to key humanitarian actors as a result of expressed needs, lessons learned, and agreements on cooperative reporting. Information of a general and historic nature will be complemented by regularly updated holdings that cover, for example, specific groups (political, religious, ethnic) or the situation in specific areas. Such literature, in and of the public domain, will be the result of linkages to holdings in remote databases, like those developed by the World Food Programme (WFP), Food and Agriculture Organization (FAO), United Nations High Commissioner for Refugees (UNHCR), International Committee of the Red Cross (ICRC) and the International Federation of the Red Cross and Red CrescentSocieties, as well as to the country reports ( which include financial tracking and early warning alerts ) offered by DHA On-Line.

Full use will be made of the latest information and communications technology to search for, and link with, existing online sources and, later, to 
regionally-based information centres. Finally, there is a need for summaries of situation reports available daily on potential "hot" spots or in the midst of an emergency. No provision has as yet been made regarding responsibility for such reporting.

\section{Emergency/Logistical}

In order to provide timely and credible information, and to be recognized as authoritative on the major aspects of the provision of information needed for emergency preparedness and response, ReliefWeb will require information that is essentially operational in nature and not always readily available in the public domain. In order to achieve maximum coverage, reports from regionally-based information centres will be essential as will agreements and compliance from participating agencies in supplying up-to-date information that covers, for example, assessments of risk and need, interactive maps that feature logistical and deployment-specific information, as well as links to registers of emergency management capacities and reference materials like field handbooks and specialized contact lists.

\section{Standards}

Information is not neutral. The user must judge the reliability of content and the biases in reporting, and the sources of that information must be recognized as reliable. Here standards develop over time. Certain sources are inherently reliable, but only because time and challenge have worked their effect. Other sources need backup. In each case corroboration helps. And it always helps to know the source of a report: if it is an NGO, what is its philosophy? If an intergovernmental organization, what is its mandate? If a newspaper, what are its politics? If a government, what is its record in the area of human rights and the rule of law? If a report by a UN rapporteur, what mandate determined its content, and under what restrictions? Even the most "objective" information can be subject to manipulation either directly or by inference.
Judging the reliability of information is essential, just as it is also important not to rule out any particular source. On the contrary, a coherent body of information requires multiple sources, each ideally have something to corroborate or qualify in the other. By avoiding single reports of events as presumptively expert in favour of contrasting various reputable points of view, allows for all-important challenge and criticism. In practice, public domain sources appear more than adequate, while confidential information has its role in the protection of sources under certain circumstances.

ReliefWeb will aim to address this controversial issue of sources by identifying the source, who is the author or issuing authority, as well as the date of issue. To ensure the reliability of such identification, the ReliefWeb Project Team will develop a banner-type system which will feature title headers for each screen of information. Moreover, ReliefWeb will feature a search engine that allows for string searching and multiple results across a broad range of data. These efforts, along with the possibility of accessing multiple sources of information on similar topics will allow for comprehensive searches of a wide range of information as well as the potential for comparison and contrast of sources which allows for all-important comment and challenge.

\section{Further Considerations}

ReliefWeb cannot deliver solutions. What it can do, if well-planned, supported, and resourced, is to act as a kind of navigator to sources of information whose nature, scope, and timeliness will necessarily inform decision making.

With the addition of regional information centres, it could, for the first time in history, provide for ongoing management of information in trouble spots, early identification of trends, and, during emergencies, keeping major actors and the world informed on a daily basis. All this is now possible with modern information and communications technology.
What is still required, however, is the political will to cooperate on the advancement of a global network for the good of the humanitarian community and not simply in the interests of a single agency or self-styled consortium. An initiative of this magnitude requires agreement at the highest level and matching resources to ensure that such a system will be realized.

These are the challenges facing the idea of ReliefWeb today. Success for the Project is a double-edged sword. On one hand, without major effort on the part of the Project Team to deliver on substance and value-added modalities, the Project cannot expect future resourcing. On the other, in order to take the Project to a level of viability, investment now, and for the next five years, is an absolute prerequisite to success. Without it, ReliefWeb will remain a mandate statement and nothing more.

Continued from page $17 /$ The Role of International Alert ...

Beyond. Conference sponsored by Synergies Africa, The North-South Centre and International Alert, Lisbon.

Alker, H., T. Gurr, and K. Rupesinghe. 1995. Conflict and Early Warning Systems; An Initial Research Programme. Chicago, February.

Boutros-Ghali, B. 1992. An Agenda for Peace. United Nations, New York.

Daws, S. 1993. Preventive Diplomacy-Report Of A Round Table On Preventive Diplomacy And The UN's Agenda For Peace. International Alert, UNU, NIRA, London.

Diamond, L., and J. McDonald. 1993. Multitrack Diplomacy: a systems approach to peace, (3rd edition). West Hartford, CT: Kumarian Press.

International Alert. 1994a. The Challenge for Peacemaking in Africa: Conflict Prevention and Resolution. October 1994.

-1994b. Regional Mechanisms for Early Warning and Preventive Diplomacy in Africa. October 1994.

Siccama, J. G. (ed). 1996. Conflict Prevention and Early Warning in the Political Practice of International Organisations. Clingendael Report. $\square$ 